\title{
Humanismo e arte para uma geografia do conhecimento*
}

\author{
Eduardo Marandola Júnior ${ }^{* *}$
}

\section{Resumo}

A capacidade de produzir arte faz parte daquilo que torna o homem único. A ciência moderna, no entanto, tratou de dissociar arte de pensamento e, com isso, ciência de arte. A Geografia, enquanto ciência moderna, respeitou essa separação, embora em certos momentos tenha se utilizado de descrições artísticas como ilustração para seus trabalhos, em especial as literárias. Nas reestruturações epistemológicas contemporâneas, no entanto, reconduzir a Geografia para seu encontro com a Arte é tanto necessário quanto imprescindível para seu desenvolvimento. Isso não ocorre apenas pela incorporação da arte como documento, mas, sobretudo como símbolo e marca de um espaço-tempo cultural. Este trabalho parte da contribuição seminal de Wright sobre a geosofia, procurando um entendimento da arte enquanto conhecimento geográfico no contexto do humanismo em Geografia.

Palavras-chave: Geosofia; Epistemologia; Humanismo em Geografia; John K. Wright.

Uma primeira versão deste texto foi apresentada no Grupo de Discussão Matrizes do pensamento geográfico, realizado durante o I Colóquio Brasileiro de História do Pensamento Geográfico, ocorrido de 27 a 30 de Abril de 2008 na cidade de Uberlândia, MG.

** Geógrafo, Núcleo de Estudos de População, Universidade Estadual de Campinas - NEPO/Unicamp (eduardom@nepo.unicamp.br).

Geosul, Florianópolis, v. 25, n. 49, p7-26, jan./jun. 2010 
MARANDOLA JR. E. Humanismo e arte para uma geografia do ...

Humanism and art towards a geography of knowledge

\begin{abstract}
The ability to produce art is part of what makes humans unique. Modern science, however, tried to dissociate art from thinking and, therefore, the science of art. Geography, as a modern science, has respected this separation, although at times it has used artistic descriptions as an illustration to their work, especially literary work. In the contemporary epistemological restructuring, however, to bring Geography to its encounter with Art is both necessary and essential to their development. This occurs not only by the incorporation of art as a document, but rather as a symbol and a mark of cultural space-time. This article starts from the seminal contribution of Wright on the subject of Geosophy, seeking an understanding of art as a geographical knowledge in the context of Humanism in Geography.
\end{abstract}

Key words: Geosophy; Epistemology; Humanism in Geography; John K. Wright.

John K. Wright, em seu discurso presidencial da Associação dos Geógrafos Americanos, proferido em 1946, defendeu que a imaginação era o que diferenciava um geógrafo de outros cientistas ou pessoas (WRIGHT, 1947). Ele não apenas defendeu que os geógrafos precisam se abrir para o conhecimento produzido fora da ciência formal, como também insistiu que há geografia para além da academia. Para ele, o conhecimento geográfico possui uma natureza que não é de propriedade exclusiva de geógrafos profissionais. Ele aponta seriamente para a importância de olharmos para "além das fronteiras", onde outros também produzem conhecimento geográfico de relevância.

Entre eles, sem dúvida, os artistas têm papel de destaque. Com grande sensibilidade, têm fornecido importantes leituras e construções de realidades que são de interesse não apenas do geógrafo, mas também de historiadores, sociólogos, antropólogos, 
MARANDOLA JR. E. Humanismo e arte para uma geografia do ...

psicólogos e filósofos. Esta incorporação possui pelo menos dois eixos principais: (1) como relato documental, apegando-se à realidade retratada e àquilo que ela traz de facticidade históricogeográfica; e (2) como imagem-imaginário ou símbolorepresentação, que traz/produz uma visão de mundo (valores e símbolos), desenhando geografias e proporcionando a reflexão sobre a própria condição humana; um conhecimento universal portanto.

A partir da idéia da obra de arte enquanto imagemimaginário, podemos entender a proposta de Wright de ampliar os horizontes do conhecimento geográfico em direção a uma geografia do conhecimento.

The realm of geography - geography in the sense of all that has been written and depicted and conceived on the subject - consists of a relatively small core area (to borrow Whittlesey's phrase) and a much broader peripheral zone. The core comprises formal studies in geography as such; the periphery includes all of the informal geography offers little of value to us, some of it shows an insight deep into the heart of the matters with which we are most closely concerned. I venture to think that, of two geographers equally competent in all other respects, the one the better read in the imaginative passages in English literature dealing with the land of Britain could write the better regional geography of that land (WRIGHT, 1947, p.10).

Wright não opõe ou contrapõe os tipos de conhecimento. Para ele, era tão importante a pesquisa científica do geógrafo (Geografia formal) quanto a leitura dos romances regionais (geografia informal). Era uma visão bastante sofisticada para a época, momento de regozijo das concepções cientificistas acadêmicas e de separação abissal entre Ciência e Arte.

Procuro perseguir as idéias de Wright, iniciando um caminho que põe em pauta a discussão sobre a Geosofia no contexto do Humanismo em Geografia, apontando para suas possíveis relações e a importância de buscar o conhecimento geográfico para além das fronteiras disciplinares do saber acadêmico. 
MARANDOLA JR. E. Humanismo e arte para uma geografia do ...

\section{Conhecimento geográfico e humanismo}

Jostein Gaarder costuma dizer que as crianças são filósofas por natureza, pois sua curiosidade e vontade de saber são os sentimentos inatos e característicos de todo filósofo (GAARDER, 1996). A curiosidade está intimamente ligada à observação e esta, segundo Sauer (2005), é aspecto fundamental do geógrafo, aquilo que o distingue. A curiosidade identifica semelhanças e diferenças, nota detalhes e busca a explicação compreensiva da forma, como que um "olhar morfológico".

A curiosidade caminha junto com um impulso ao novo e ao desconhecido, um desejo de saber e entender o mundo à nossa volta. Esses desejos, no entanto, diminuem com o passar do tempo. É raro encontrar adultos tão ávidos por entender tudo, em seus pequenos detalhes ou particularidades, como o são as crianças. Talvez a confiança que temos nos conhecimentos que já adquirimos nos acomodem na falsa segurança de nossas posições. Não nos questionamos nem nos inquietamos mais; acomodamos-nos. Delimitamos nosso mundo num campo conhecido de ação, reagindo a cada movimento que tente nos levar para além dele, ou que traga elementos além-mundo. Nos entrincheiramos como soldados que defendem sua vida em termos de posições num mapa de estratégia.

Nem todos, no entanto, fazem esta travessia completa. A curiosidade, que é inata às crianças, pode tanto ser mantida ao longo do tempo quanto cultivada em alguns "campos" da nossa vida. E é esta curiosidade que impulsiona não apenas os filósofos, mas todo cientista, artista e pessoa que deseja "ir além".

$\mathrm{O}$ além do pensamento às vezes é mais distante de nós do que o além da época anterior às grandes navegações. $O$ "alémmar", o "além império", as "terras ermas" ou o "além república" representam formas de etnocentrismo baseadas na diferenciação do conhecido e do não-conhecido, do incluído e do não-incluído, do dominado e do não-dominado. Orientam não apenas o traçado de territórios, mas sobretudo delimitam a visão de mundo de uma cultura. 
MARANDOLA JR. E. Humanismo e arte para uma geografia do ...

É evidente que esta curiosidade possui várias facetas, que culminaram nos diferentes campos do saber humano que, cada um à sua maneira, busca ampliar as fronteiras do conhecimento, sempre tentando ir além, vencendo objeções, suplantando escuridões inacessíveis e imaginando como poderiam ser os territórios ainda desconhecidos. Esta gana de conhecer cada vez mais nos é inerente e permeia também nossa ciência geográfica, desde sua origem mais remota.

Wright (1947) foi uma das principais vozes na primeira metade do século XX a dar importância a esta característica inata dos geógrafos, buscando tornar cognita terras ainda incognitae. $\mathrm{O}$ fascínio pelo ainda não visto e o desejo de estar e conhecer lugares nunca vistos (chamado pelo autor de libido geográfica), estimularam a imaginação de exploradores, viajantes e naturalistas que se propuseram a explorar o mundo, impulsionando-os em suas jornadas.

No entanto, Wright acreditava que essa tarefa de ampliação do conhecimento do mundo não se extinguiu quando tivemos o mapa-múndi completamente desenhado ou quando já estivemos potencialmente em todos os pontos do planeta. Ele aponta para a diferença entre as terrae incognitae científicas e as pessoais, pois cada um de nós possui experiências e conhecimentos individuais, que constituem verdadeiros microcosmos, um egocentrismo. Tudo aquilo que não conhecemos é potencialmente perigoso. Nosso mundo possui os limites do nosso conhecimento e cognição. Nesse caso, além de buscarmos o contínuo desenho de terrae incognitae que ainda não foram exploradas pelo nosso campo disciplinar, avançando pelas fronteiras interdisciplinares, precisamos estar atentos para a importância dos conhecimentos que não têm origem científica. O conhecimento geográfico é inerente à própria realidade e está sendo constituído no cotidiano das pessoas, na efetivação de políticas no campo, em intervenções urbanas, em escritos literários, em manifestações culturais, em crenças religiosas. Toda ação humana possui uma dimensão espacial que se revela por meio de uma espacialidade que conduz o vir-a-ser do fenômeno. 
MARANDOLA JR. E. Humanismo e arte para uma geografia do ...

Este conhecimento geográfico é chamado por Wright de geografia informal, ou periférica, contrapondo-se à geografia formal, institucionalmente sistematizada pelos geógrafos profissionais. Para estes, no entanto, um desafio é incorporar ao conhecimento produzido a geografia daqueles, desenvolvendo uma geografia do conhecimento, ou geosofia, que estaria ocupada em investigar o conhecimento produzido geograficamente, desde qualquer ponto de vista (WRIGHT, 1947, p.12).

Hoje, este apelo de Wright soa como um desejo de transcender o conhecimento formal produzido através de conceitos e categorias científicas em direção a uma geografia essencial, que se revela no cotidiano e na vida de todos. É um esforço na direção da geograficidade, tal como trabalhada por Dardel (1952), enquanto envolvimento visceral entre homem e meio, produzindo a essência do relacionamento espacial do homem e de sua natureza geográfica. Incorporar esta geografia (conhecimento informal) à nossa Geografia (conhecimento formal) é um desejo humanista que tem sido perseguido no contexto acadêmico em especial por um grupo de geógrafos que tem se identificado com os princípios do Humanismo.

Essas preocupações são especialmente relevantes hoje. Os tempos em que vivemos são de profunda consternação com respeito à desumanidade que impera nas decisões políticas e na forma de condução e negociação das questões em geral. Nunca o homem foi tão atacado em sua condição humana, seja pelas guerras e invasões, seja pelos riscos e perigos que o ameaçam constantemente, oriundos tanto de eventos físicos (desastres ambientais) quanto da própria sociedade e da tecnologia (perigos sociais e tecnológicos).

Nesse contexto, o Humanismo é resgatado. No entanto, não é possível falar de um Humanismo, mas de humanismos, pois há muitos significados associados ao termo (NOGARE, 1975). Mas a principal dificuldade não é a questão conceitual. O drama atual é tentar pensar em humanismo no contexto da crescente desumanização. Ser humanista, hoje, é mais do que empunhar bandeiras ou defender os "direitos humanos", o que se aproxima 
MARANDOLA JR. E. Humanismo e arte para uma geografia do ...

mais de humanitarismo. Ser humanista também é muito mais do que se preocupar com o próximo ou fazer o bem. Ser humanista, defendo aqui, envolve pensar e fazer prosperar o que há de humano no homem: sua humanidade.

Para um grande conhecedor da cultura italiana do renascimento, "humanismo é a descoberta do homem enquanto homem, e consequentemente a reafirmação de tudo que é humano." (SILVA, 1986 - grifo do autor). Este entendimento de um humanismo relacionado à elevação dos fenômenos essencialmente humanos está associado a uma filosofia que se caracteriza enquanto "conjunto de princípios doutrinais referentes à origem, natureza, destino do homem." (NOGARE, 1975, p.13).

Este sistema de pensamento está esteado em alguns princípios evocados por humanistas de diferentes épocas. Por exemplo, no caso do humanismo renascentista, encontramos alguns princípios que permanecem importantes para a composição de um sentido de um humanismo contemporâneo, útil à prática geográfica. A partir de Abbagnano (1970), extraí os seguintes pontos fundamentais: (1) Reconhecimento da totalidade do homem, destinado a viver no mundo com dignidade e liberdade, um valor supremo para os humanistas; (2) Reconhecimento da historicidade do homem, seus vínculos com o passado, tanto de vínculo quanto de contraposição. Nesse sentido, vincula-se a necessidade do conhecimento de códigos, imagens, literatura e poesia, juntamente com a necessidade de reencontrar o seu autêntico significado, ou da verdade filosófica e religiosa; (3) Reconhecimento do valor humano das letras clássicas. Este aspecto é o que atribui o nome ao movimento, pois desde a Antigüidade a palavra humanitas significava a educação do homem como tal, não como fim, mas como meio para a formação de uma consciência, aberta em todas as direções, por meio do conhecimento histórico-crítico da tradição cultural; e (4) Reconhecimento da naturalidade do homem, ou seja, do fato de que o homem é um ser natural. Assim, conhecer a natureza não é um pecado, mas uma necessidade e um dever. 
MARANDOLA JR. E. Humanismo e arte para uma geografia do ...

É evidente que muitos destes enunciados não possuíam significados idênticos aos de hoje, pois as próprias noções de liberdade, naturalidade e dignidade, por exemplo, possuem referências históricas muito específicas. No entanto, podemos, através de uma atualização de conceitos, contextualizá-los na contemporaneidade enquanto fundamentos de uma visão holística do homem e da natureza, admitindo a importância da cultura e da história no devir sociopolítico, estando a liberdade e a dignidade no alto dos valores humanos.

Por outro lado, filosoficamente, Abbagnano (1970, p.494) assinala que o humanismo pode ser "tôda filosofia que faça do homem, de acôrdo com a antiga sentença de Protágonas, 'a medida das coisas." Eis um ponto primordial: o homem como o valor a ser colocado à ciência. O autor conclui: "Em sentido mais amplo, pode-se entender por Humanismo qualquer caminho filosófico que tome em consideração as possibilidades e, pois, os limites do homem e que proceda, nesta base, a uma reordenação dos problemas filosóficos". Eis um sentido fundamental para o Humanismo defendido aqui: além de colocar o homem enquanto medida e valor para o trabalho científico, é necessário defender a exploração de suas potencialidades, suas possibilidades, seus sentimentos e suas virtudes, em busca do conhecimento e dos nossos próprios limites, servindo de base para um reordenamento dos problemas científicos da Geografia.

A razão, além da arte, foi resgatada pelo humanismo renascentista enquanto fenômeno essencialmente humano. Ambas cumpriam à finalidade de libertar o homem da razão divina para poder delinear seus próprios caminhos. No entanto, ironicamente, a razão se converteu na grande deusa da modernidade (RELPH, 1981). Ou como Bunkse (1990, p.106) assinala: "In the final analysis, humanism is about the quality of civilization, its habitats, and the human condition. It is not about materialistic, anthropocentric, or egocentric greed - at least not as an ideal."

Hoje, o esforço humanista é de relativizar a razão, colocando nos mesmos termos a emoção, a imaginação, a percepção e outras 
MARANDOLA JR. E. Humanismo e arte para uma geografia do ...

"ações" que tenham suas forças motrizes no esforço criativo e intuitivo. $\mathrm{O}$ conhecimento geográfico, enquanto essência do relacionamento homem-meio, é um destes conhecimentos que compõem nossa realidade multifacetada e necessitam de um olhar específico para serem incorporados à nossa Geografia. Entre estes encontram-se tanto a imaginação estética, esteada na subjetividade (WRIGHT, 1947) quanto o conhecimento experiencial vivido existencialmente.

Heidegger (1991), por outro lado, resgata um sentido para o Humanismo na cultura helênico-romana. É no civismo romano, no culto às humanidades (arte, filosofia, sabedoria), que se opunha à barbárie além fronteiras que o filósofo irá encontrar elementos essenciais para pensar o que chama de humanismo supremo. Enquanto cientistas, nos esforçamos em resgatar este sentido do humano, não enquanto conceito ou bandeira, mas no seu significado ontológico. O que busco com a evocação de Heidegger é um sentido, uma direção: o Humanismo que pode permear a Ciência, em geral, e a Geografia, em particular, é aquele que tem no homem seu peso e valor; homem como fim e meio para a Ciência (MARANDOLA JR., 2005). A arte é uma das principais expressões dessa humanidade. No entanto, é necessário ter a medida certa de sua natureza e vínculos com o espaço e a cultura.

\section{A arte como símbolo da cultura e do espaço}

As teorias sobre a arte são tão variadas quanto as suas formas. Tentar organizar estas manifestações de forma objetiva pode ser um caminho tão espinhoso quanto a sua complexidade. Não se pretende transformar o conhecimento subjetivo ou coletivo, simbolicamente materializados dessas manifestações, em conhecimento objetivo e sistematizado. O que buscamos são as marcas que a arte imprime no espaço, como também as marcas que o espaço inscreve na arte.

Arte é pensamento, construído e materializado num determinado símbolo-imagem. "Para conseguir ser um artista, é 
MARANDOLA JR. E. Humanismo e arte para uma geografia do ...

necessário dominar, controlar e transformar a experiência em memória, a memória em expressão, a matéria em forma", lembra Fischer (1971, p.14). A produção artística é um trabalho racional, argumenta o autor, não fruto de um estado de inspiração embriagante, sendo necessário aprender a tratar a emoção, transmitindo-a e transformando-a. A obra de arte é, portanto, uma realidade dominada, com o uso de técnicas, recursos, convenções, sentidos e emoções.

O trabalho artístico é um trabalho de criação. Merleau-Ponty (2006) salienta o processo de vir a ser do Ser que, através da experiência e consciência que este tem de si e do mundo, ganha, nas artes, visibilidade (artes plásticas), som (música), movimento (teatro) e intangibilidade (literatura, poesia). Chauí (1994), comentando a obra do filósofo, ressalta a necessidade de romper as amarras da tradição do pensamento filosófico-científico, que somente vê o mundo de forma oblíqua e indireta, separando o visível do invisível, o dizível do indizível, o pensável do impensável, a matéria do espírito, e assim por diante. A obra de arte, segundo Chauí, é evocada como forma que não manipula e sim maneja as coisas e que, "ruminando o mundo", jamais abandona "sua inerência a ele, mas, de dentro dele, o transfigura para que seja verdadeiro sendo que é quando encontra quem saiba vê-lo ou dizê-lo, isto é, quem consiga arrancá-lo de si mesmo para que seu sentido venha à expressão". Ao invés de um simulacro da realidade, a obra de arte transcende o Ser, sendo o artista um "[...] sentinela em vigília às portas do sensível" (MERLEAU-PONTY apud CHAUÍ, 1994, p.471).

O ensinamento maior da arte para a filosofia é, na concepção de Chauí (1994), de que o pensamento não pode estar fixo em um único pólo, no visível ou no invisível, no racional ou no intuitivo. Segundo a autora, o pensamento e a experiência estão justamente no movimento entre dois pontos, os quais são inseparáveis e intrínsecos. Ela afirma ainda que "a experiência e o pensamento são passagem de um termo por dentro do outro, passando pelos poros do outro, cada qual reenviando ao outro sem cessar", 
MARANDOLA JR. E. Humanismo e arte para uma geografia do ...

concluindo como impossível, a delimitação objetiva da realidade e a desconsideração dos intrincados mecanismos da mente humana e de seus simbolismos e formas de organização.

Nas obras de arte, vemos inscritas as duas dimensões que aparentemente se confrontam: o material e o simbólico, o racional e o intuitivo. Contudo, essa diametria precisa ser melhor refletida, pois o material sem o simbólico inexiste e o simbólico, conforme aponta Mukarôwvský (1993), embora subsista sem o material, não se torna uma manifestação, veículo de cultura e comunicação, sem uma dada materialização.

Arte e pensamento são completamente comunicáveis e interligados. Novaes (1994, p.9) anota o ponto de confluência dos dois fenômenos: "o desejo da experiência desmensurada do obscuro e do ausente", na busca da realidade oculta do pensamento, através de diferentes formas de expressão. Tanto Merleau-Ponty como Paul Valéry, defenderam a falácia da separação e uniram-nos na qualidade de um campo, num movimento de liberdade, capaz de transcender as condições de fato, nas quais nos encontramos, dandonos um sentido novo. A obra de arte, afirma Novaes, é um movimento de pensamento e liberdade.

As obras de arte são símbolos, ou seja, objetos dotados de significado, de acordo com Mukaröwvský (1993). Quem lhes atribui esses significados? Quem é capaz de interpretá-los? A semiologia compreende cada vez melhor que o conteúdo da consciência individual é dado, até a sua maior profundidade, pelos conteúdos da consciência coletiva. Desta forma, o autor salienta que a questão da significação e dos signos se impõe, haja vista que o conteúdo psíquico, quando ultrapassa os limites da consciência individual, adquire o caráter de signo. Mukarôwvský aponta as ciências do espírito para dar conta da compreensão das três categorias presentes na obra de arte: estrutura, valor e signo.

$\mathrm{O}$ signo é um fator sensorial que se refere a uma realidade e que por meio dela se pretende evocar (MUKARÔWVSKÝ, 1993). Esta realidade é tanto a realidade material quanto simbólica, social e cultural, econômica e política, ambiental e técnica. Na medida 
MARANDOLA JR. E. Humanismo e arte para uma geografia do ...

em que as relações socioculturais se complexificam, complexificam-se também as manifestações artísticas e seu entendimento semiológico, conforme nos mostra Fischer (1971). No entanto, Mukarôwvský afirma que, tanto em sociedades chamadas "primitivas", quanto em sociedades contemporâneas, a cultura e a sociedade serão elementos chave para a compreensão da obra de arte.

O autor aponta que a arte, como criação humana, está em relação permanente com as outras esferas da realidade: produção dos bens materiais (artesanato, produção industrial etc.) e com as esferas dos valores espirituais (filosofia, ciência, religião, ideologia). Ele mostra a relação que estas esferas têm com a arte:

A estrutura da arte é constituída por um conjunto de normas que estão na consciência colectiva, o que explica os contactos com o sistema linguístico, com o sistema ético, com os 'costumes' que determinam o comportamento do homem (as normas de conduta social, as regras da prática da vida, etc.) [...] Mas é exactamente a arte que demonstra com clareza que nem as relações entre a cultura e o homem nem as relações entre as várias esferas da cultura são unívocas: e, na realidade, a obra de arte pode vir a ser característica não só da sociedade, nação, etc. em que apareceu como também da sociedade, nação, etc. que recebe a obra já pronta, embora a organização desta sociedade e a sua atitude perante a realidade sejam diferentes da organização e da atitude noética da sociedade que efectivamente a criou (MUKARÔWVSKÝ, 1993, p.241)

A arte é assim concebida por Mukarôwvský (1993) como pertencente à sociedade humana, produção entendível em seu contexto histórico-cultural específico. "A arte não evoluiu no vazio, antes se encontra perante as influências, que lhe chegam do exterior", afirma o autor, demonstrando que não é possível desvincular a obra de arte da história e do contexto social, como também deve ser levada em consideração a afetividade e a singularidade do artista. Somente o peso correto entre as forças 
MARANDOLA JR. E. Humanismo e arte para uma geografia do ...

atuantes, internas e externas, determina coerentemente o sentido das evoluções.

Esse aspecto cognitivo da produção artística foi bem expresso por Lévy (1998), um filósofo que se dedica a estudar as formas de cognição e inteligência do homem. Ele destacou que as manifestações artísticas somente podem ser compreendidas mediante o conhecimento do conjunto de significações simbólicas daquela determinada cultura, o qual é constituído socialmente através do tempo. Por exemplo, Lévy comenta que as obras italianas do renascimento somente possuem sentido na medida em que nos informamos da situação em que vivia a Itália e a Europa em todos os campos da vida e do conhecimento. Fora deste contexto, as obras perdem o sentido ou, em última análise, adquirem outro sentido, específico às novas formas espaçotemporais. As obras de artes estão embebidas por este simbolismo. Para a sua compreensão é necessário o conhecimento da história e da cultura, como um mergulhar no "ambiente" de criação.

Há uma relação entre espaço e tempo indissociável, trazendo história, cultura e geografia para o centro da compreensão da manifestação artística. Esta relação histórica da obra de arte é demarcada no momento da percepção da obra, conforme nos relata Argan. Neste momento é que será possível reconhecer, no julgamento de valor, a dimensão da cultura na arte, conforme salienta o autor:

A percepção assinala sempre e apenas o tempo do presente absoluto. A arte, cujo valor se dá na percepção, torna presentes os valores da cultura no próprio ato em que os traduz e reduz a seus próprios valores. Não atua num setor do saber próprio, específico: tudo pode ser estruturado ou organizado como arte, assim como tudo pode ser estruturado ou organizado como filosofia. $\mathrm{O}$ que o chamado juízo de valor verifica na obra de arte não é, decerto, a conformidade a uma determinada cultura, nem a sua superação, mas uma estrutura cultural específica, justamente aquela graças à qual os valores podem ser 
MARANDOLA JR. E. Humanismo e arte para uma geografia do ...

captados, não na dimensão sem tempo do pensamento abstrato, mas na do presente absoluto, da percepção. (ARGAN, 1995, p.26)

Contudo, a dimensão cultural não é o elemento determinante da produção artística. O próprio Argan (1995) nos lembra que a arte, como estrutura cultural, diz respeito à matéria estruturada, de um lado, e ao processo de estruturação, de outro. Desta forma, continua o autor, identifica-se em cada objeto artístico um sedimento de noções que o artista tem em comum com a sociedade de que faz parte, atribuída à história e à cultura. Argan menciona que pode existir outra camada, compreendendo as idéias sobre a arte e as preferências artísticas, os conhecimentos técnicos, as normas ou tradições iconográficas as quais o artista se filia ou escolhe. Por fim, o autor menciona a existência de uma última camada, cuja configuração escapa à análise conduzida segundo modelos culturais determinados, por constituir-se na contribuição pessoal, inovadora do artista. Esta última camada nos interessa pelo seu caráter subjetivo e sua filiação ao campo estreito da fruição da consciência, materializada na forma de signos na obra de arte. Além do mais, a mediatização da cultura dá-se também na constituição do sentir do artista e de seu trabalho ímpar e original, na construção de uma concepção única do meio em que vive, porém, o fato de ser única, não a qualifica como inválida. Antes, denota que possuímos um universo muito grande para compreender a realidade.

Adentramos assim no infindável universo da consciência, da imaginação e da memória. Compreendê-lo é um provocante norte, que guia filósofos, artistas e cientistas já por séculos. Nesse meio, Argan (1995) afirma que o dinamismo estrutural da obra de arte é o da relação funcional entre a operação técnica e o mecanismo da memória e da imaginação, trazendo freqüentemente à tona elementos que nos instrumentalizam para resolver os problemas que se apresentam, às vezes escondidos em profundidades remotíssimas da psiquê. 
MARANDOLA JR. E. Humanismo e arte para uma geografia do ...

O indivíduo não o é sozinho. Da mesma forma, a cultura não existe sem os indivíduos. Assim, os constructos e símbolos humanos não devem ser, segundo Fischer (1971, p.13), considerados como obra de um ou de outro. A consubstanciação é inerente, sendo a obra de arte um "meio indispensável para essa união do indivíduo com o todo; [a arte] reflete a infinita capacidade humana para a associação, para a circulação de experiências e idéias". Isto nos possibilita a composição de um conteúdo histórico e cultural mais preciso, refletido em diversos olhares, que se fundem e se complementam.

\section{Geosofia: ciência e arte}

O conhecimento essencial, aquele que poderíamos chamar de verdadeiro, está para além das fragmentações do saber. Não está nem no sujeito, nem no objeto. Está exatamente na relação que se estabelece entre a consciência e o mundo: ali acontece o revelar-se, o vir-a-ser do fenômeno (HEIDEGGER, 2002). Mas o desafio de reintegrar os saberes é extenso e exige, acima de tudo, desprendimento.

Contudo, as maiores transformações que precisam ser gestadas estão em nossas paisagens interiores. Somos nós que temos de nos refazer, incorporando estas geografias enquanto verdades tão concretas quanto a solidez aparente de nossos números, fórmulas e modelos. As fronteiras do conhecimento geográfico estão muito além deste ponto onde chegamos aqui, neste pequeno vôo exploratório. Elas se estendem aos confins da Terra e precisam ser ainda intensamente exploradas, pois a Geografia e as geografias se redesenham a cada dia, e é necessário fôlego para acompanhá-las.

A busca de um Humanismo em Geografia é uma tarefa que passa por esta exploração. Como Carlos Augusto de F. Monteiro nos alerta, "a 'condição humana' em sua 'interioridade' [...] intimamente ligadas ao substrato psíquico dos indivíduos humanos não poderão ser alcançados através de algorítimos. Se sentimentos 
MARANDOLA JR. E. Humanismo e arte para uma geografia do ...

não são passíveis de quantificar, procuremos a análise psicológicopsicanalítica e a criação - mesmo ficcional - literária." (MONTEIRO, 2002, p.48) O Novo Humanismo que o autor acredita que possa estar em gestação, para o futuro, considera que em meio às nossas imensas diferenças, há um substrato comum: nossa "humanidade". E este sentido humano essencial está expresso de forma mais evidente no conhecimento experiencial vivido quotidianamente, nas produções artísticas, nas culturas e saberes populares, na memória e no imaginário das cidades.

A arte, para Monteiro (2005), é reveladora dos sentidos mais profundos do mundo. $\mathrm{O}$ sentir do artista é uma produção/extração de sentido do mundo, das coisas, do ser e dos entes. Assim, o momento atual, de reconstrução da razão, do conhecimento e do humanismo, é visto pelo autor como o momento de afastar a ciência de sua pretensão e admitir a arte como manifestação cultural do maior interesse e sintonia com a ciência. Monteiro se afasta de uma noção dicotômica que associa de forma maniqueísta razão de ciência e sentimento da arte, que aponta para a mesma direção que Wright, há mais de 60 anos, instava que os geógrafos buscassem.

Uma geosofia ainda poderá ser desenhada no futuro. Mas talvez o principal não seja a sua sistematização, mas sim a mudança de atitude diante do outro. Os geógrafos precisam reaprender a contemplar, com olhar lírico, as paisagens e os lugares. Tanto a terra quanto os homens merecem nossa atenção e ele nos leva a entender, uma vez mais, que estes são indissociáveis e enlaçados para sempre.

Assim também se encontram Ciência e Arte, que temos que urgentemente reaproximar. A Arte, assim como a Ciência, também brota da relação orgânica do homem com o meio, e por isso é tão importante para a Geografia. Nas manifestações artísticas estão inscritas geografias da mesma forma que foram necessárias geografias para concebê-las. Tanto o conhecimento existencial do artista quanto seus referenciais culturais estão embebidos de 
MARANDOLA JR. E. Humanismo e arte para uma geografia do ...

geograficidade, pois esta é inalienável do ser humano e de suas realizações.

A criação artística e a criação científica, por outro lado, não estão tão distantes entre si quanto a tradição moderna salienta. "A criação artística não é desprovida de roteiros e de procedimentos referenciados por contextos históricos e culturais", assim como a Ciência técnicas e procedimentos são elaborados de acordo com processos e "[...] paradigmas de contexto, organizados e referenciados pela harmonia, pela estética, por balizas culturais." (HISSA, 2002, p.131) Ambas se encontram em uma viagem metafórica, possuindo método e instrumentos que as conduzem ao seu objetivo. É neste sentido que Adauto Novaes, por exemplo, usa o termo artepensamento, pois a manifestação artística não é pura intuição: a razão, a lógica, a emoção, a sensação e a imaginação estão presentes tanto na manifestação artística quanto no trabalho científico (NOVAES, 1994).

A Geografia tem aprendido muito nos últimos anos com escritores, com artistas plásticos, com cineastas e principalmente com aqueles que possuem o conhecimento geográfico experiencial, vivido. Esses demarcam territórios, seja simbolicamente ou materialmente (MARANDOLA JR. e FERREIRA, 2001), além de descreverem de forma única paisagens e lugares (DARBY, 1977). Cada qual ajuda-nos a compor o grande atlas do mundo, revelando particularidades e apontando para verdades universais. $\mathrm{O}$ mais significativo é que estes conhecimentos reforçam a importância do ser humano em sua relação orgânica com o ambiente, tornando os valores científicos e artísticos ainda mais próximos. Por outro lado, questionam a prática do geógrafo enquanto cientista racional, na busca apenas da aplicabilidade e da comprovação. Somos levados a refletir sobre nossa prática (ética), nossas teorias (epistemologia) e sobre o próprio sentido do conhecimento geográfico (geosofia) e sua natureza (ontologia).

O caminho aberto por Wright ainda não foi trilhado em toda sua extensão, e a geografia do conhecimento ainda está longe de estar completa. Com ela, a Geografia se abre para as geografias e 
MARANDOLA JR. E. Humanismo e arte para uma geografia do ...

se aproxima tanto de um humanismo contemporâneo em busca do significado e do sentido do ser quanto de uma epistemologia desenraigada e aberta que permita acompanhar com maior desenvoltura as rápidas transformações socioespaciais contemporâneas.

\section{Referências bibliográficas}

ABBAGNANO, Nicola. Humanismo. In: Dicionário de filosofia. São Paulo: Mestre Jou, 1970. p.493-494.

ARGAN, Giulio C. História da arte como história da cidade. 3ed. (trad. Pier L. Cabra) São Paulo: Martins Fontes, 1995.

BUNKSE, Edmunds V. Saint-Exupéry's Geography Lesson: Art and Science in the creation and cultivation of landscape values. Annals of the Association of American Geographers, v.80, n.1, p.96-108, 1990.

CHAUÍ, Marilena. Merleau-Ponty: obra de arte e filosofia. In: NOVAES, Adauto. (org.) Artepensamento. São Paulo: Cia. das Letras, 1994.

DARBY, H.C. El problema de la descripción geográfica. In :RANDLE, P. H. (ed.) Teoría de la geografía. (segunda parte). Buenos Aires: GAEA, 1977. p.231-251.

DARDEL, Eric. L'Homme et la Terre: nature de la réalité géographie. Paris: PUF, 1952. 133p.

FISCHER, Ernest. A necessidade da arte. (trad. Anna Bostock) Rio de Janeiro: Zahar Editores, 1971.

GAARDER, Jostein. O dia do curinga. (trad João Azenha Jr.) São Paulo: Cia. das Letras, 1996. 378p. 
MARANDOLA JR. E. Humanismo e arte para uma geografia do ...

GIDDENS, Anthony. Modernidade e identidade. Rio de Janeiro: Jorge Zahar, 2002. 233p.

HEIDEGGER, Martin. Carta sobre o humanismo. (trad. Rubens E. Frias) São Paulo: Moraes, 1991. 50p.

. Ser e tempo - parte I. (trad. Márcia de S. Cavalcante) 12ed. Petrópolis: Vozes, 2002. 325p.

HISSA, Cássio E. V. A mobilidade das fronteiras: inserções da Geografia na crise da modernidade. Belo Horizonte: Ed. UFMG, 2002.316p.

LÉVY, Pierre. A máquina do universo: criação, cognição e cultura informática. (trad. Bruno Charles Magne) Porto Alegre: ArtMed, 1998.

MARANDOLA JR., Eduardo. Humanismo e a Abordagem Cultural em Geografia. Geografia, Rio Claro, Ageteo, v.30, n.3, p.393-420, set./dez. 2005b.

MARANDOLA JR., Eduardo e FERREIRA, Yoshiya N. Arte e cultura como demarcadores do espaço. Scientific Journal, Bauru, SBPN, v.5, n.1, p.263-264, 2001.

MERLEAU-PONTY, Maurice. L'Ceil et l'Espirit. Paris : Gallimard, 2006.

MONTEIRO, Carlos A. de F. Interioridade-exterioridade no homem: reflexões sobre tendências atuais na Geografia e em seu possível papel na construção de um Novo Humanismo. Conferência proferida no $3^{\circ}$ Simpósio Nacional sobre Espaço e Cultura, realizado pelo NEPEC, na Universidade do Estado do Rio de Janeiro, dia 24 de outubro de 2002. 54p. [inédito] 
MARANDOLA JR. E. Humanismo e arte para uma geografia do ...

. O sentimento do mundo entre Ciência (Geografia) e a Arte (Poesia Dramática) no nascedouro do Brasil. São Paulo: FFLCH/USP, 2005. 48p. [Aula Inaugural]

Mukarôwvský, Jan. Escritos sobre estética e semiótica da arte. (trad. Manuel Ruas) Lisboa: Estampa, 1993.

NOGARE, Pedro D. Humanismos e anti-humanismos. Petrópolis: Vozes, 1975. 290p.

NOVAES, Adauto. Constelações. In: . (org.) Artepensamento. São Paulo: Cia. das Letras, 1994.

RELPH, Edward. Rational landscapes and humanistic geography. London: Croom Helm, 1981.231p.

SAUER, Carl O. A educação de um geógrafo. Geographia, Niterói, ano II, n.4, p.137-150, 2000. Disponível em: $<$ http://www.uff.br/geographia/rev_04/carl\%20o. \%20sauer.pdf>

SILVA, Benedito. Humanismo. In: . (coord.) Dicionário de Ciências Sociais. Rio de Janeiro: FGV, 1986.

WRIGHT, John K. Terrae incognitae: the place of the imagination in Geography. Annals of the Association of American Geographers, v.37, p.01-15, 1947. 